Tropical Journal of Pharmaceutical Research October 2014; 13 (10): 1593-1600

ISSN: $1596-5996$ (print); 1596-9827 (electronic)

(C) Pharmacotherapy Group, Faculty of Pharmacy, University of Benin, Benin City, 300001 Nigeria.

All rights reserved.

Available online at http://www.tjpr.org

Original Research Article

http://dx.doi.org/10.4314/tjpr.v13i10.4

\title{
Formulation and Evaluation of Two-Pulse Drug Delivery System of Amoxicillin Trihydrate
}

\author{
Rohitash Kumar, Anvesh MS, Mohammed S Khan, Afrasim Moin* and Gowda \\ DV \\ Department of Pharmaceutics, JSS College of Pharmacy, JSS University, SS Nagar, Mysore - 570015 Karnataka
}

*For correspondence: Email: afrasimmoin@yahoo.co.in

Received: 6 September 2013

Revised accepted: 19 August 2014

\begin{abstract}
Purpose: To develop a pH-controlled two-pulse drug delivery system of amoxicillin in order to overcome the snag of biological tolerance and to improve bactericidal activity.

Methods: The core tablets were compressed and coated with hydroxylpropyl methylcellulose (HPMC) of different viscosities with spray-dried lactose (SDL) as a pore former. The final two-pulse release tablet was prepared with the remaining drug fraction (to be released as the first immediate release pulse) with a disintegrant, giving the final tablet. The tablets were evaluated for pharmaceutical properties including disintegration, thickness, hardness, friability and weight variation and by DSC (differential scanning calorimetry) and FTIR (Fourier transform infrared spectroscopy) studies in order to assess drug/polymer compatibility. The tablets further subjected to in vitro dissolution studies and stability studies.

Result: The tablet core disintegrated within 30 to $40 \mathrm{~s}$. Drug content ranged from 97.85 to $98.23 \%$. FTIR and DSC studies showed drug-polymer compatibility. The developed two-pulse release tablets had acceptable thickness, hardness, friability and weight variation. In vitro drug release showed prolongation of lag time as polymer viscosity increased. With $25 \%$ HPMC and $75 \%$ SDL, drug release was $97.5 \%$ by the end of 8th , 9th \&10th $h$ and viscosity was 100, 400 and 4000 cps respectively. No significant difference in drug release was found as values were within limits of confidence interval ( $p<$ 0.05). The formulation was stable.

Conclusion: The developed formulation demonstrates the feasibility of a two-phase release of amoxicillin separated by a well-defined time-controlled lag phase which is desirable for chronotherapeutic drug delivery.
\end{abstract}

Keywords: Two-pulse drug delivery, Chronotherapeutic drug delivery, Bacterial drug resistance, Amoxicillin

Tropical Journal of Pharmaceutical Research is indexed by Science Citation Index (SciSearch), Scopus, International Pharmaceutical Abstract, Chemical Abstracts, Embase, Index Copernicus, EBSCO, African Index Medicus, JournalSeek, Journal Citation Reports/Science Edition, Directory of Open Access Journals (DOAJ), African Journal Online, Bioline International, Open-J-Gate and Pharmacy Abstracts

\section{INTRODUCTION}

Controlled-release formulations have several advantages over immediate-release formulations, such as less frequent drug administration, lower plasma peak concentration to avoid adverse effects, and improved patient compliance. Principles of delayed release delivery have lately been applied in developing a newer version of drug delivery, popularly known as chronotherapeutic drug delivery system. Such systems are developed based on the concept of biological/circadian rhythm or chronopharmacological behavior of symptom manifestation of specific conditions such as asthma, hypertension and allergic rhinitis $[1,2]$. 
Pulsatile drug delivery system (PDDS) is a type of time-controlled DDS (Drug delivery system). It may be classified as a single-unit or multiple-unit system by application of different coating systems. Multiple-unit PDDS units can be fabricated by coating multi-particulates with a $\mathrm{pH}$ dependent barrier membrane, then, by blending variously coated multi-particulates, the desired release profile is obtained [3]. An ideal pulsatile system is the one delivering drug in different pulses with multiple troughs in release profile and this technology is called as PULSYS technology [2]. Amoxicillin is a well-known amino penicillin commonly used in the treatment of streptococcal infections. It demonstrates good bioavailability throughout the entire GI tract and has been used to treat a variety of respiratory infections including otitis media, sinusitis, bronchitis and community-acquired pneumonia [4].

The purpose of the present study is to formulate and evaluate a two-pulse drug delivery system for amoxicillin trihydrate using a swellable polymer, such as HPMC, that would serve as a drug release barrier that results in drug release at two different times in order to minimize development of bacterial resistance as well as improve patient compliance.

\section{EXPERIMENTAL}

\section{Materials}

Amoxicillin trihydrate (Zest Pharma, India), HPMC 100, 400 and 4000 cps, (Signet) Croscarmellose sodium (Ac-di-sol) (Micro labs, Kudlu, Bangalore), Sodium starch glycollate and Polyvinyl pyrollidine (Povidone k 30) (Micro labs, kudlu, Bangalore, India), Spray dried lactose (SDL) and magnesium stearate (Central Drug House, India) were used. All other reagents were of analytical grade and were used as received.

\section{Pre-formulation studies}

\section{Micromeritics}

The angle of repose of the tablet core blend, compression coating material and immediate release formulation was determined by the fixed funnel method. Loose bulk density (LBD) and tapped bulk density (TBD) were determined using a density apparatus (Serwell Instruments, Bangalore, India). Carr's index (\%) and the Hausner ratio were calculated as described elsewhere [5-7].

\section{Infrared spectroscopy (FT-IR)}

Infrared spectra were taken by using $\mathrm{KBr}$ pellet technique using a Shimadzu FT-IR 8300 Spectrophotometer (Shimadzu, Tokyo, Japan) in the wavelength region of 4000 to $400 \mathrm{~cm}-1$. The procedure consisted of dispersing a sample (drug alone or mixture of drug and excipients or formulation) in $\mathrm{KBr}$ and compressing into discs by applying a pressure of 5 tons for $5 \mathrm{~min}$ in a hydraulic press. The pellet was placed in the light path and the spectrum obtained [7].

\section{Differential scanning calorimetry (DSC)}

Differential scanning calorimetry (DSC) scans were performed using a DSC-60 (Shimadzu, Tokyo, Japan) calorimeter. The instrument comprised of a calorimeter (DSC 60), flow controller (FCL 60), thermal analyzer (TA 60) and operating software (TA 60). The samples (drug alone or mixture of drug and excipients or formulation) were heated in perforated aluminum pans under nitrogen flow $(30 \mathrm{ml} / \mathrm{min})$ at a scanning rate of $10{ }^{\circ} \mathrm{C} / \mathrm{min}$ from 30 to $240{ }^{\circ} \mathrm{C}$. Indium was used as a reference.

\section{Preparation of core tablets}

The granules were prepared by wet granulation method. The dry ingredients (drug + disintegrant) were passed through sieve \#40 and mixed. PVP $\mathrm{K}-30(4 \% \mathrm{w} / \mathrm{v})$ in purified water was used as a binder. The wet granules were dried at $50{ }^{\circ} \mathrm{C}$ for $4 \mathrm{~h}$. The dried granules were passed through sieve \#20. The resultant granules were mixed with glidant, colloidal silicon dioxide $(0.5 \% \mathrm{w} / \mathrm{w})$ and finally lubricated with magnesium stearate $(0.5 \% \mathrm{w} / \mathrm{w})$. Then processed granules were compressed into tablets using $9 \mathrm{~mm}$ standard concave punch at 10-station rotary tablet machine (Rimek mini press, Mumbai). Mean hardness of the compressed core tablets was 42 $\pm 0.50 \mathrm{~N}$. The tablets were then stored in an airtight polyethylene bag and protected from moisture until they were coated [5].

\section{Coating to the core tablets}

$9 \mathrm{~mm}$ diameter tablet cores were compressioncoated into $11 \mathrm{~mm}$ diameter tablets using various HPMC compression-coating formulations (432 mg; 108-432 mg of HPMC 100 Cps, HPMC 400 Cps and HPMC K4M, and $0-324 \mathrm{mg}$ of spray dried lactose for 25-100 \% HPMC polymer compression-coating). The compression-coated tablets (core:coat, 1:2) were prepared by first filling one-half $(216 \mathrm{mg}$ ) of compression-coated powders in the die cavity, then centrally positioning the tablet core on the powder bed 
followed by filling the remaining half $(216 \mathrm{mg})$ of the polymer powder on top and then by compression at $145 \quad 0.5 \mathrm{~N}$, as previously described [8].

\section{Optimization of lag time of two-pulse drug release system}

The desired lag time of the formulation between the two pulses was set at 2 to $4 \mathrm{~h}$. The lag time of the core tablet was optimized by coating the core with different levels of the coating material (HPMC of different viscosities) and in vitro release behavior was studied

\section{Evaluation of effect of pore former concentration}

In the present study, directly compressible lactose was used as a pore former. The concentration of pore former was studied by keeping the spray dried lactose concentration 0 to $75 \% \mathrm{w} / \mathrm{w}$ in 25 to $100 \% \mathrm{w} / \mathrm{w}$ HPMC concentration (Table 2).

\section{Preparation of final two-pulse release tablet}

After optimizing the core tablet and attaining the desired release profile, the final two pulse tablet was prepared in the form of an inlay tablet design. The tablet was prepared in a semi automatic manner by compression coating. The granules for final layer were prepared by wet granulation method according to the formula given in the Table 1 . To prepare inlay tablet the bottom of the die cavity $(12.7 \mathrm{~mm}$ standard concave punch) was filled with prepared granules (Table 1) and the compression coated tablet core was placed upon it. Due to pushing of the core tablet, the blend became displaced from

Table 1: Formula for inner most and outer most layer of tablets

\begin{tabular}{lll}
\hline Tablet layer & Ingredient & Quantity (mg per tablet) \\
\hline & Amoxicillin trihydrate & 200 \\
& Ac-Di-sol (5\%) & 10 \\
& Povidone K30 (2\%) & 4 \\
Core tablet (inner layer) & Purified Water & QS \\
& Magnesium stearate & 1 \\
& Aerosil & 1 \\
& Total weight of core tablet & $216 \mathrm{mg}$ \\
& Amoxicillin & 300 \\
Compression coating & Sodium starch glycolate & 10 \\
blend (outer layer) & Povidone K30 (2\%) & 6 \\
& Purified water & 1 \\
& Magnesium stearate & $\mathrm{QS}$ \\
& Aerosil & 1 \\
& Amaranth & 0.5 \\
\hline
\end{tabular}

${ }^{*} Q S$ : Sufficient quantity

Table 2: Composition of barrier layer material

\begin{tabular}{lll}
\hline Tablet layer & Ingredient & Quantity (mg per tablet) \\
\hline & Amoxicillin trihydrate & 200 \\
& Ac-Di-sol (5\%) & 10 \\
Core tablet (inner layer) & Povidone K30 (2\%) & 4 \\
& Purified Water & QS \\
& Magnesium stearate & 1 \\
& Aerosil & 1 \\
& Total weight of core tablet & $216 \mathrm{mg}$ \\
& Amoxicillin & 300 \\
Compression coating & Sodium starch glycolate & 10 \\
blend (outer layer) & Povidone K30 (2\%) & 6 \\
& Purified water & 1 \\
& Magnesium stearate & QS \\
& Aerosil & 1 \\
\hline
\end{tabular}

Note: Each tablet contained $2 \mathrm{mg}$ each of magnesium stearate and colloidal silicon dioxide; total weight of each tablet was designed to be $436 \mathrm{mg}$ 
the bottom and rearranged in the clearance between the core tablet and die wall, resulting in coverage of the core tablets from all sides, except for the top surface [2]. The hardness of the final tablet was kept at $190 \pm 0.5 \mathrm{~N}$. The pattern of tablet cleavage during the hardness test was monitored. The tablet cleaved from the centre without separation of the core and the surrounding layer. Polymer coating over the core for the two pulse design by compression machine was done because high polymer loading was not possible with pan coating and small amount of polymer was not sufficient to delay drug release for 3 to $4 \mathrm{~h}$. A full compression coat (complete coating from all sides) for the polymer coated core could have been applied with the final drug fraction (instead of coating the core partially/incompletely). This was not done to provide patient compliance by avoiding bigger size of the tablets. The prepared inlay tablet is being a combination of an immediate release and delayed release component.

\section{In vitro release studies}

In vitro drug release studies were performed by using a USP reciprocating dissolution test apparatus (USP apparatus $3,37 \pm 0.5^{\circ} \mathrm{C}$ ) in $\mathrm{pH}$ 1.2 hydrochloric acid buffer $(300 \mathrm{ml})$ for $2 \mathrm{~h}$ as the average gastric emptying time. Then, the dissolution medium was replaced with a $\mathrm{pH} 6.8$ phosphate buffer and dissolution studies was carried out till complete drug release was obtained. The amount of drug released from the tablets at different time intervals was determined spectrophotometrically at $237 \mathrm{~nm}$ (Shimadzu UV1208). All experiments are done in triplicate.

\section{Stability studies}

Optimized formulation was selected to assess the stability as per $\mathrm{ICH}$ guidelines. Optimized formulation was sealed in aluminum foil coated inside with polyethylene and kept inside stability chamber maintained at $40 \pm 2{ }^{\circ} \mathrm{C}$ and $75 \pm 5 \%$ $\mathrm{RH}$ for 3 months. The samples were analyzed for drug content and in vitro dissolution at the end of the period.

\section{Statistical analysis}

A one-way ANOVA with Tukey's post hoc test was used to analyze the dissolution data obtained for each batch of formulation in order to compare the rate of drug release from the matrix tablets. Confidence limit was set at $95 \%$.

\section{RESULTS}

\section{Micromeritic properties}

The results of micromeritic properties are presented in Table 3 . Values for angle of repose 20-30 ${ }^{\circ}$ generally indicate good flow property. A Hausner ratio of less than 1.25 and Carr's index of 12-16\% also indicates good flow [6]. Granules prepared for immediate release and outer layer showed good flowability. Angle of repose was within the 25 to 26, Carr's index was found 12 to $15 \%$ and Hausner ratio was found 1.14 to 1.16 .

\section{Drug-excipient compatibility}

The absorption peak of the drug with tertiary $-\mathrm{OH}$ groups exhibited a broad peak around $3300 \mathrm{~cm}^{-1}$

Table 3: Micromeritic properties of barrier layer material

\begin{tabular}{lccc}
\hline $\begin{array}{l}\text { Batch } \\
\text { code }\end{array}$ & $\begin{array}{c}\text { Angle of repose }(\boldsymbol{\theta}) \\
\text { Mean } \pm \text { SD* }\end{array}$ & $\begin{array}{c}\text { Carr's index }(\mathbf{C l}) \\
\text { Mean } \pm \text { SD }^{*}\end{array}$ & $\begin{array}{c}\text { Hausner's ratio (HR) } \\
\text { Mean } \pm \text { SD }^{*}\end{array}$ \\
\hline C1 & $28.04 \pm 0.28$ & $13.07 \pm 0.38$ & $1.137 \pm 0.28$ \\
C2 & $29.17 \pm 0.18$ & $14.01 \pm 0.22$ & $1.161 \pm 0.32$ \\
C3 & $30.25 \pm 0.21$ & $16.34 \pm 0.16$ & $1.195 \pm 0.21$ \\
C4 & $31.01 \pm 0.23$ & $17.69 \pm 0.38$ & $1.200 \pm 0.28$ \\
C5 & $25.25 \pm 0.19$ & $12.20 \pm 0.29$ & $1.13 \pm 0.18$ \\
C6 & $26.23 \pm 0.18$ & $14.0 \pm 0.25$ & $1.15 \pm 0.24$ \\
C7 & $30.15 \pm 0.11$ & $15.88 \pm 0.35$ & $1.19 \pm 0.23$ \\
C8 & $31.45 \pm 0.32$ & $16.0 \pm 0.32$ & $1.21 \pm 0.25$ \\
C9 & $25.6 \pm 0.28$ & $13.91 \pm 0.13$ & $1.135 \pm 0.16$ \\
C10 & $27.1 \pm 0.25$ & $14.05 \pm 0.17$ & $1.157 \pm 0.17$ \\
C11 & $30.7 \pm 0.23$ & $15.91 \pm 0.23$ & $1.189 \pm 0.14$ \\
C12 & $32.4 \pm 0.26$ & $16.6 \pm 0.18$ & $1.20 \pm 0.19$ \\
\hline
\end{tabular}

${ }^{*} S D=$ standard deviation, $n=3$ 
and a $\mathrm{C}=\mathrm{O}$ group which is in the form of a lactum ring, exhibited a strong peak near 1770 $\mathrm{cm}^{-1}$. The aromatic $\mathrm{C}-\mathrm{H}$ peaks are also observed around $1500 \mathrm{~cm}^{-1}$ as shown in Figure 1. From the results obtained for drug-excipient compatibility study, it is found that the drug is compatible with the respective excipients under evaluation based on physical observation. So the chosen excipients could be used in the formulation trials.

\section{Thermal characteristics}

The DSC thermograms of one of the formulations and pure amoxicillin showed endothermic peaks at 294.4 and $298.9{ }^{\circ} \mathrm{C}$, respectively, corresponding to amoxicillin (Figure 2).
Disintegration test showed that core tablets disintegrated within 30 to $40 \mathrm{~s}$. Drug content was 97.85 to $98.23 \%$. All tablet cores (without compression-coating) resulted in complete drug release within $15 \mathrm{~min}$ (data not shown).

\section{Polymer coating to the core tablets}

The core tablets were coated with vaying viscosities of HPMC (100, 400 and $4000 \mathrm{cps})$ with a pore former (spray dried lactose) using compression-coating techniques. In vitro release data are shown in Figure 3. The hardness of the coated tablets was kept in the range of 140 to $150 \mathrm{~N}$.

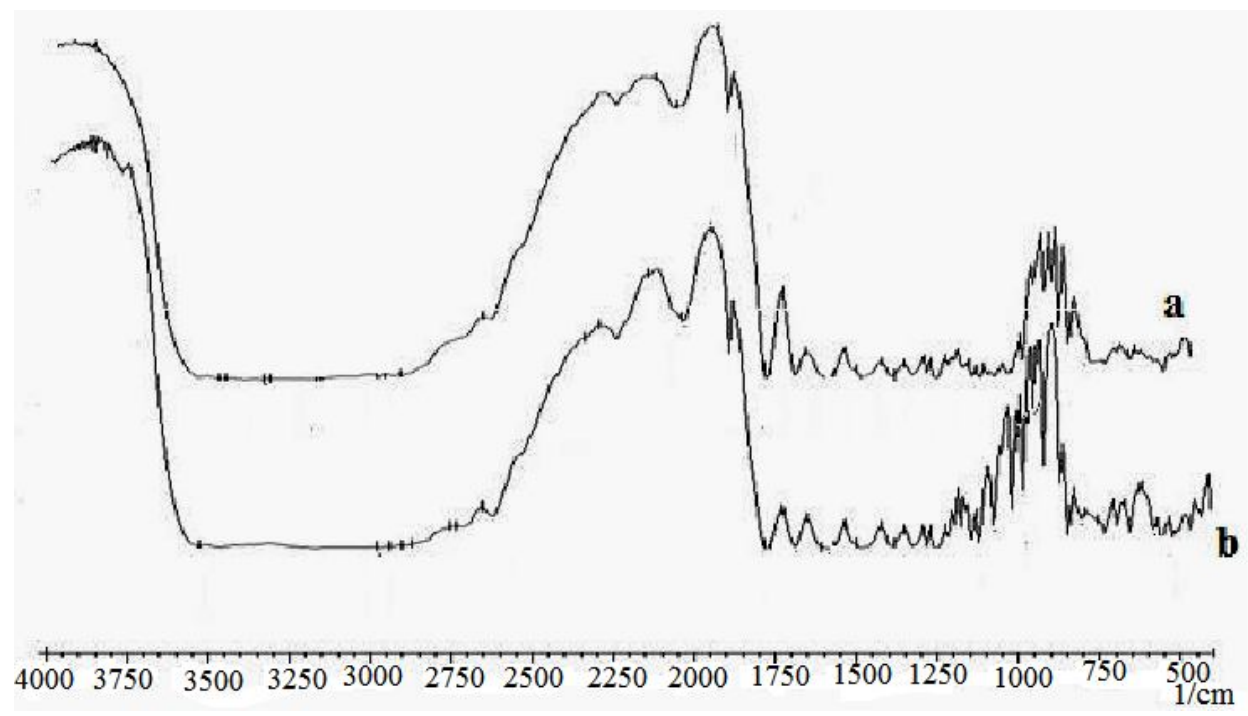

Figure 1: FTIR spectra of (a) pure drug and (b) formulation (C4)

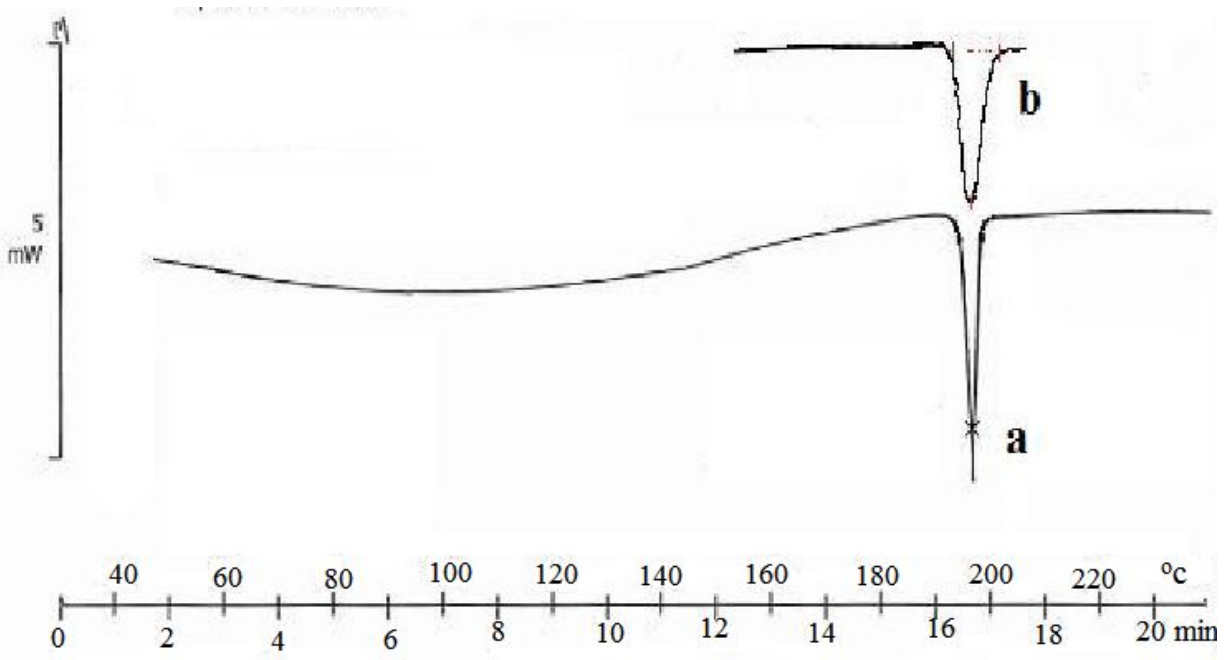

Figure 2: DSC thermograms of pure drug (a) and formulation (C4) 

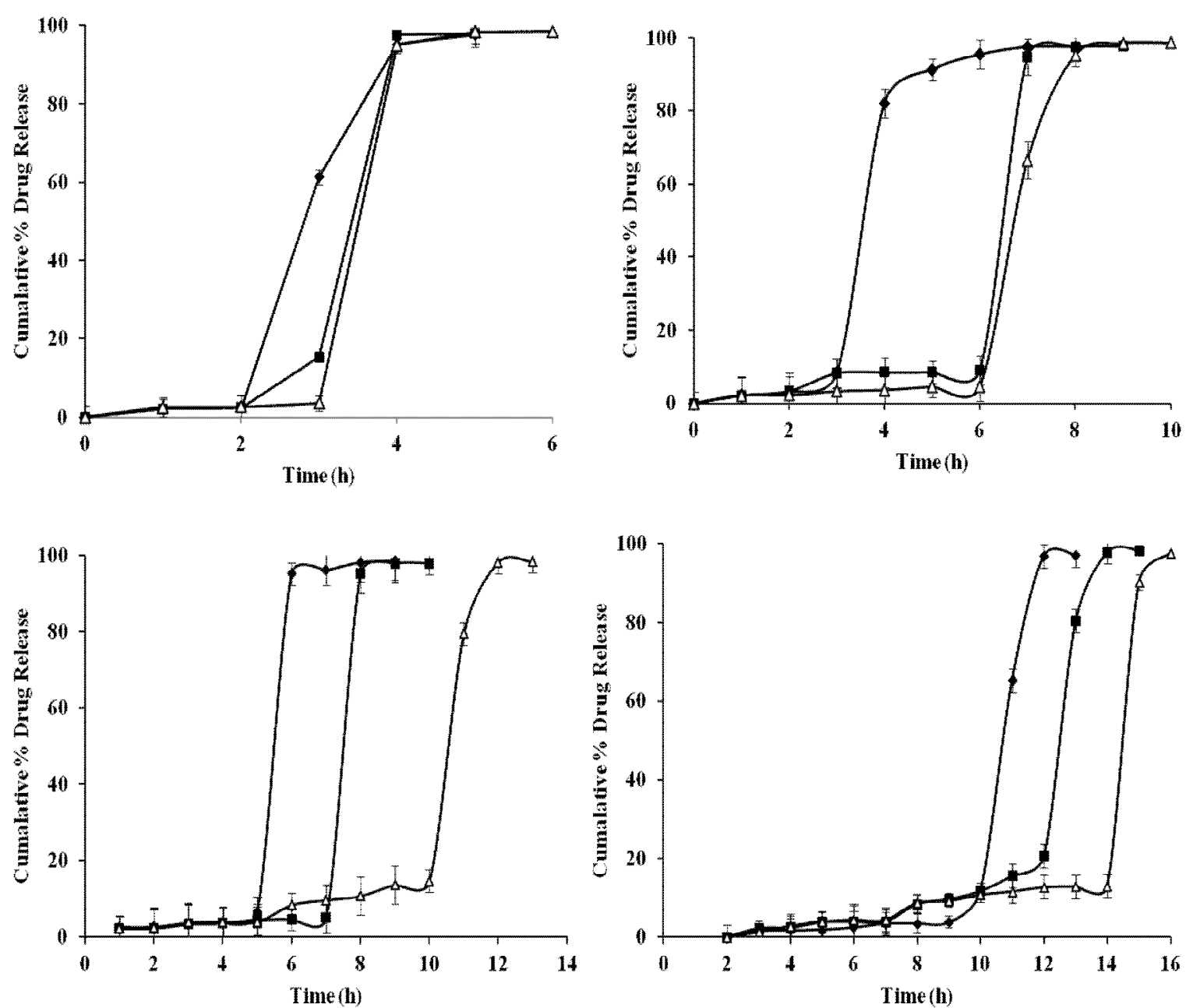

Figure 3: Effect of HPMC-type and amount of spray dried lactose (25 \% HPMC to $75 \%$ SDL) on drug release from HPMC compression-coated tablets (core:coat, 1:2, 9mm tablet cores in 11mm compression-coated tablets) (A) HPMC $25 \%$ and $75 \%$ SDL, (B) HPMC $50 \%$ and $50 \%$ SDL, (C) HPMC $75 \%$ and $25 \%$ SDL, (D) HPMC 100 $\%$ and $0 \%$ SDL

\section{Effect of barrier layer}

The lag-time and the release rate was controlled by varying the composition (ratio HPMC/spray dried lactose) and the amount of the polymer (HPMC) in compression-coating as to polymer concentration was increased from 25 to $100 \%$. This resulted in increase in the lag time as the polymer composition is increased, swelling increase and fluid penetration decrease as a result more lag time for second pulse release.

\section{Final two-pulse release tablets}

Based on these in vitro release studies, tablets which gave lag time in the range of 2- $4 \mathrm{~h}$, were selected for final two pulse release inlay tablets. Out of 12, formulations $\mathrm{C} 1, \mathrm{C} 5, \& \mathrm{C} 9$ were selected for final two pulse release inlay tablets (Figure 4). The results of the evaluation of final inlay tablets for various parameters like thickness, hardness, and friability as pre specified limit is shown in Table 4.

Table 4: Evaluation parameter for final two pulse release tablets

\begin{tabular}{clll}
\hline $\begin{array}{c}\text { Batch } \\
\text { code }\end{array}$ & Weight variation & $\begin{array}{l}\text { Hardness (N) (Mean } \pm \\
\left.\mathrm{SD}^{*}\right)\end{array}$ & $\begin{array}{l}\text { Friability (\%) } \\
\left(\text { Mean } \pm \mathrm{SD}^{*}\right)\end{array}$ \\
\hline C1 & Pass & $185 \pm 0.23$ & $0.42 \pm 0.115$ \\
C5 & Pass & $187 \pm 0.32$ & $0.44 \pm 0.15$ \\
C9 & Pass & $186 \pm 0.27$ & $0.46 \pm 0.2$ \\
\hline
\end{tabular}

${ }^{*} S D=$ standard Deviation, $n=3$ 


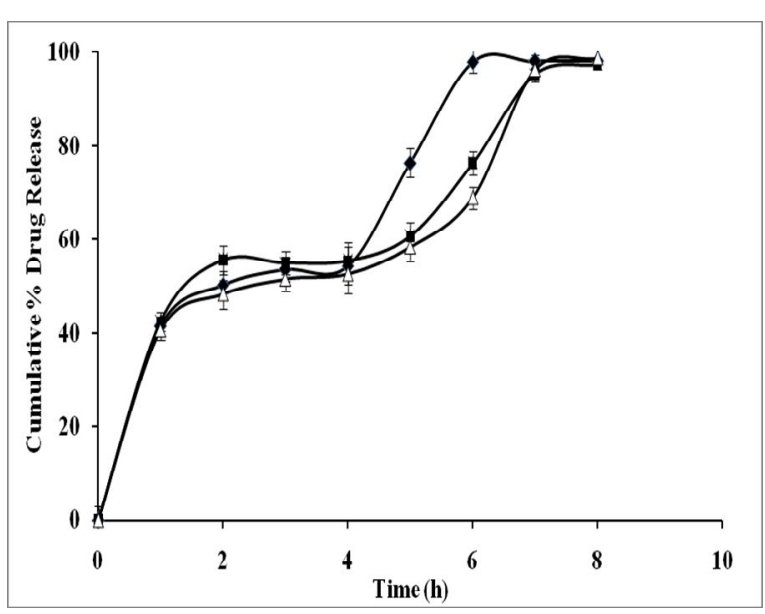

Figure 4: Drug release from two-pulse tablets. from C1,C5 and C9: C1 (- - HPMC 25\% 100cps), C2 (- HPMC 25\% 400 cps) ,C3 (- $\Delta$ - HPMC 25\% 4000cps)

\section{DISCUSSION}

For direct compression of materials, it is required to possess good flow and compacting properties. Blend for compression coating (barrier layer) showed good flowability shown in Table 3, which were prepared by direct compression method.

Drug excipients interaction studies by FT-IR spectroscopy revealed characteristic absorption peaks of formulations as shown in Figure 1 and the results suggested that the drug is compatible with the respective excipients used, under evaluation based on physical observation. So the chosen excipients could be used in the formulation trials. The DSC endothermic peaks for the pure drug and the drug in the test formulation showed only a negligible shift in their positions with some peak broadening in the latter. Thus, the likelihood of any chemical interaction between the drug and the polymers used can be ruled out.

The HPMC compression-coated tablets hydrated and swelled around the drug cores. Depending on solubility, drugs are released from HPMC matrix either through diffusion or erosion of the gelled HPMC matrix [9]. In contrast, increasing the viscosity grade (molecular weight) of HPMC in the compression-coating did not affect the release of the drug. The initial release phase was the same with the different HPMC grades because of a release mechanism of diffusion through the gel. The lower viscosity grade HPMC $100 \mathrm{cps}$ eroded faster and thus resulted in an earlier completeness in release. Lag time was pre-determined as 3 to $4 \mathrm{~h}$. The rationale of getting the desired lag time of 3 to $4 \mathrm{~h}$ is that designed two pulse tablets are given three times a day (every $8 \mathrm{~h}$ ). Hence the first pulse is immediate release like the conventional release profile and the expected time to release the drug is about $1.5 \mathrm{~h}(300 \mathrm{mg}$, the first dose to maintain the plasma drug concentration up to MIC and before the concentration falls below MIC); the next pulse of drug release (lag time, 3 to $4 \mathrm{~h}$ ) would be complete in $1.5 \mathrm{~h}(200 \mathrm{mg})$ and will maintain drug concentration for another $2 \mathrm{~h}$. Therefore, the overall time to accomplish the drug release for one tablet is $(1.5+3+1.5+2)$, i.e., $8 \mathrm{~h}$.

Due to pushing of the core tablet, the blend became displaced from the bottom and rearranged in the clearance between the core tablet and die wall, resulting in coverage of the core tablets from all sides, except for the top surface [2]. The hardness of the final tablet was kept at $90 \pm 0.5 \mathrm{~N}$. The pattern of tablet cleavage during the hardness test was monitored. The tablet cleaved from the centre without separation of the core and the surrounding layer. Drug dose was divided into two parts: core tablet $(200 \mathrm{mg})$, compression coating blend (300 mg). Polymer coating over the core for the two pulse design by compression machine was done because high polymer loading was not possible with pan coating and small amount of polymer was not sufficient to delay drug release for 3 to $4 \mathrm{~h}$. A full compression coat (complete coating from all sides) for the polymer coated core could have been applied with the final drug fraction (instead of coating the core partially/incompletely). This was not done to provide patient compliance by avoiding bigger size of the tablets. The prepared inlay tablet is being a combination of an immediate release and delayed release component.

In vitro release studies of two pulse release inlay tablet showed that the outer layer of the tablet constitutes the first pulse, which released the drug in the stomach within $1 \mathrm{~h}$; the second pulse gave delayed release after a preset lag time of 2 to $4 \mathrm{~h}$ in phosphate buffer. All the 3 formulations C1, C5 and C9 exhibited the complete drug release up to 7 th hour. An evident decrease in the lag phase and a corresponding increase in the drug release were observed with increasing concentrations of SDL (O to $75 \% \mathrm{w} / \mathrm{w}$ ) in the compression coating material. This is attributed to the fact that SDL formed fine pores/channels over the tablet surface on contact with water and hence early exit of the drug from the channels might be possible at higher concentration. Outer layer of the tablet constitutes the first pulse, which simulates drug release in the stomach (first $1 \mathrm{~h}$ ); the second pulse gave delayed release after a preset lag time of 2 to $4 \mathrm{~h}$ in phosphate buffer to simulate intestinal release. 
After 3 months of storage, at $40 \pm 5$ and $75 \pm 5 \%$ $\mathrm{RH}$, the formulation was characterized for in vitro drug release, drug content, and hardness. No significant difference in drug release was found as values were within confidence intervals limits of $95 \%$. The drug content was found to be 48.14 $+0.35 \%$. The hardness was also within the limits varying between $6.4 \pm 0.23 \mathrm{~kg} / \mathrm{cm}^{2}$.

\section{CONCLUSION}

A two-pulse drug delivery system for amoxicillin has been successfully achieved in this study release. This delivery system can potentially be employed to minimize bacterial resistance against antibiotics. The results indicate that HPMC provides an effective barrier layer for a well-defined time-controlled drug release in two pulses. Thus the developed system is a suitable candidate for chronotherapeutic delivery.

\section{REFERENCES}

1. Traynor D, Newton DW, Hrushesky JM, Reiter RJ. A pharmacist primer on chronotherapeutics. Am. Phar 1992; 32: 261-269.
2. Saigal N, Baboota S, Ahuja A, Ali J. Multiple-pulse drug delivery systems: setting a new paradigm for infectious disease therapy. Expert Opin. Drug Deliv 2009; 6(4): 441-452.

3. Roy $P$, Shahiwala A. Multiparticulate formulation approach to pulsatile drug delivery: Current perspectives. J. Control. Release 2009; 134: 74-80.

4. Raymond C, Michael J . Pulsatile delivery of amoxicillin against Streptococcus pneumonia. J Antimicrob Chemother 2004; 54: 1067-1071.

5. Liebermann HA, Lachman L, Schwartz JB. Pharmaceutical Dosage Forms: Tablets, vol. 2", Marcel Dekker, New York. pp 1990201-1990243.

6. Wells JI, Aulton ME. Aultons Pharmaceutics-the Design and Manufacture of Medicines, 3rd edn, Elsevier, Churchill Livingstone 2007, pp. 337-360.

7. Indian Pharmacopoeia, Ministry of Health and Family Welfare, Government of India, Vol. 2, Controller of Publication, Delhi, India, 1996.

8. Lin KH, Lin SY, Li MJ. Compression forces and amount of outer coating layer affecting the time-controlled disintegration of the compression-coated tablets prepared by direct compression with micronized ethyl cellulose. J. Pharm. Sci. 2001; 90: 2005-2009.

9. Siepmann J, Streubel A, Peppas NA. Understanding and predicting drug delivery from hydrophilic matrix tablets using the "Sequential Layer" model. Pharm. Res. 2002; 19: 306-314. 